\title{
Distance Traveled to Obtain Clinical Abortion Care in the United States and Reasons for Clinic Choice
}

\author{
Liza Fuentes, DrPH, MPH and Jenna Jerman, MPH
}

\begin{abstract}
Introduction: Greater distance to abortion facilities is associated with greater out-of-pocket costs, emergency room follow-up care, negative mental health, and delayed care among U.S. abortion patients. However, the distance U.S. abortion patients travel has not been reported since 2008, and no study has examined reasons abortion patients choose the particular facility where they obtain their abortion.

Materials and Methods: We analyzed data from the 2014 Abortion Patient Survey and Abortion Provider Census to report abortion patients' one-way travel from their resident zip code to their abortion clinic, whether they went to the closest clinic, and reasons for facility choice. We report unadjusted and adjusted associations of patients' characteristics with travel distance and differences in average travel distance by abortion patients' reported reasons for choosing their facility.

Results: In 2014, 65\% of abortion patients traveled less than 25 miles one-way, 17\% traveled 25-49 miles, and $18 \%$ traveled more than 50 miles. Abortion patients who were white, college-educated, U.S.-born, $\geq 12$ weeks pregnant, and lived outside metropolitan areas were more likely to travel farther. Nearly half of abortion patients went to their nearest provider and $32 \%$ chose their facility because it was the closest.

Conclusion: These results indicate that travel distance is an important determinant of abortion care access in the United States. Nearly, one-fifth of U.S. abortion patients traveled more than 50 miles one-way and the most common reason reported for clinic choice was that it was the closest.
\end{abstract}

Keywords: abortion, distance traveled, clinic choice

\section{Introduction}

$\mathbf{T}$ RAVEL DISTANCE IS an important determinant of access to health services, ${ }^{1,2}$ including abortion care; in 2016, the decision of the Supreme Court of the United States in Whole Women's Health v. Hellerstedt upheld that increased driving distances can contribute to an undue burden on access to abortion care. In the United States, $95 \%$ of abortions were provided in specialized clinic settings in 2014, and $39 \%$ of U.S. women of reproductive age lived in a county with no such clinic. ${ }^{3}$ In 2008, the most recent year for which there are data, $67 \%$ of U.S. abortion patients traveled less than 25 miles (one-way), and 6\% traveled more than 100 miles. In adjusted analyses, abortion patients who were white and had graduated college traveled farther on average than black and Latina patients and those who had graduated high school or less, respectively. Abortion patients who did not live in metropolitan statistical areas (MSAs), urbanized areas of 50,000 or more population, ${ }^{4}$ and those who obtained abortions beyond 12 weeks of pregnancy were more likely to travel farther than their counterparts. ${ }^{5}$

Changes in the distribution and type of abortion facilities may affect how far people must travel for abortion services. $^{6,7}$ Between 2008 and 2014, the number of abortion clinics in the United States declined 7\%, from 851 to $788 .^{3}$ During this time, three states also implemented bans on abortions to those whose pregnancies are 22 weeks or more from the last menstrual period. Some women may have had to travel farther to obtain abortion care because of clinics closures and abortion bans. However, others may have been unable to overcome the increased distance and thus prevented from obtaining abortion care at all. ${ }^{8}$

Several studies have found that greater distances to abortion facilities are associated with increased burden among patients, including higher associated out-of-pocket costs, ${ }^{7}$ greater difficulty getting to the clinic, ${ }^{7}$ negative mental health outcomes, ${ }^{9}$

Research Division, Guttmacher Institute, New York, New York.

(c) Liza Fuentes and Jenna Jerman 2019; Published by Mary Ann Liebert, Inc. This Open Access article is distributed under the terms of the Creative Commons Attribution Noncommercial License (http://creativecommons.org/licenses/by-nc/4.0/) which permits any noncommercial use, distribution, and reproduction in any medium, provided the original author(s) and the source are cited. 
higher likelihood of emergency room-based follow-up care, ${ }^{10}$ delayed care, ${ }^{11}$ and decreased use of abortion services. ${ }^{12-14}$ Similar burdens have been documented in Canada, which bears both cultural and infrastructural similarities to the United States. ${ }^{15}$ In Texas, increased distance to the nearest abortion provider after clinic closures in 2013 was associated with a decrease in the abortion rate, ${ }^{16}$ and in particular, among counties where the distance to the nearest abortion provider increased by $\geq 100$ miles, the number of abortions to county residents declined by $50 \%{ }^{17}$ Another study estimated a $69 \%$ decline in the $\geq 16$-week abortion rate to Texas residents after nonhospital $\geq 16$ week abortions became unavailable and the average distance to the nearest provider increased by 219 miles. This estimate accounted for secular decline in the abortion rate and Texas residents who still obtained out-of-state abortion care, suggesting that many women could not overcome the additional travel distance to farther facilities after their local providers closed. ${ }^{18}$

Abortion access is also determined by factors other than distance; individuals seeking abortion care must weigh preferences, needs, and available resources against considerations such as the procedure fee, health insurance coverage, availability and timing of appointments, type and severity of restrictive abortion laws where they live, type of procedure offered (medical or surgical), and pregnancy gestation limits. ${ }^{9,19}$ As a result, some patients may travel farther than their nearest abortion provider if they can, although the proportion of abortion patients who travel beyond their nearest provider, how much farther they travel, and for what reasons have not been studied in a national sample of abortion patients.

The aims of this study were to describe the distance U.S. abortion patients traveled for abortion services in 2014, the proportion of abortion patients who went to their nearest provider, and patient characteristics and reasons patients chose the facility where they obtained their abortion associated with travel distance.

\section{Materials and Methods}

This cross-sectional, descriptive study uses the 2014 Abortion Patient Survey, which is nationally representative of nonhospital abortion patients in the United States. ${ }^{20}$ This study obtained human subjects ethics approval from the Guttmacher Institute's federally registered Institutional Review Board. A detailed description of the dataset is published elsewhere ${ }^{20}$; a synopsis is provided below.

Between April 2014 and June 2015, a four-page questionnaire (available in English and Spanish) was distributed to all patients who obtained an abortion at each of 87 participating facilities; each facility's data collection period lasted a 2 to 12week fielding period inversely proportional to the facility's size. During the 14-month fielding period, facilities provided 11,024 abortions and returned 8,380 patient surveys, representing a $76 \%$ response rate. Questionnaire domains included demographic information and abortion and other reproductive healthrelated experiences, including reasons the patient selected the facility at which they were obtaining an abortion. It also requested participants' resident state and zip code. Weights were constructed to account for nonresponse, rendering the data representative of all U.S. women obtaining abortions.

We calculated two distance measures. The first was the one-way distance from each patient's resident zip code to the abortion facility where they obtained their abortion; in other words, the distance actually traveled for abortion services. We used the "traveltime3" program in Stata, which accesses the Google Maps application programming interface, to calculate driving distance in miles between patients' zip codes and facility zip codes. Distances for 33 patients for whom the areas between their zip code and abortion clinic traversed undeveloped land (i.e., forests, bodies of water) were calculated using Google Maps individually since these calculations returned errors in traveltime3. Patients who obtained abortions in their resident zip code were coded as having traveled zero miles. One-way distance traveled to the abortion facility was recorded into a categorical variable indicating less than 25, 25-49, 50-100 and >100 miles; these categories were used in previously published research. ${ }^{5}$

The second distance measure was the one-way distance to the abortion clinic nearest to each patient's zip code. Using Guttmacher Institute's 2014 database of all known abortion facilities, we found the nearest health care facility defined as a health care facility that provided at least 400 abortions in 2014, or Planned Parenthood affiliate that provided at least one abortion in 2014, by straight-line distance from each patient's zip code centroid using Maptitude. As per previous research, these metrics are meant to identify access points for abortion care that are accessible and discoverable by people seeking abortion care. ${ }^{21}$ We then calculated the driving distance using "traveltime3" and subtracted it from the distance each patient actually traveled to determine the proportion of patients who went to their nearest abortion provider, and among those who did not, how much farther than their nearest provider they traveled.*

Eight percent of abortion patients $(n=633)$ did not provide a valid zip code and were excluded from analysis. This level of missing information was similar to the overall level of nonresponse on sensitive items, and Chi-square statistics revealed that those patients for whom we lacked distance information did not differ from the full sample of patients on any characteristic (not shown). We excluded 44 patients as outliers because they traveled more than 400 miles, were vast majority $\geq 18$ years old, obtained first trimester procedures, and lived in states with multiple abortion providers. These cases likely represent students living away from home, patients traveling for vacation, to areas where friends or family reside, or for other reasons, and therefore, do not represent the typical abortion patient in terms of travel burden. Although an additional 15 patients met these same outlier criteria, we included them in the analysis because they lived in Alaska and did not cross state lines to obtain an abortion, and therefore more likely represent the typical abortion patient in their state.

We hypothesized that 14 independent characteristics and two policy measures would be associated with travel. The first policy measure was whether patients lived in a state with a waiting period law; this included "two-visit" laws

*Respondents who traveled within 1 mile of their nearest provider were coded as having traveled to their nearest provider (traveled zero miles) since Google Maps does not calculate to this level of precision (i.e. the same calculation could be more than 1 mile different on two separate tries for the same calculation). In addition, patients who traveled very small distances, such as 1 mile, beyond their nearest provider, could be traveling the same as or negligibly farther distances than their nearest provider if they lived in a geographically large zip code or on the border of their zip code. 
(requiring an in-person visit to the abortion facility followed by a waiting period of at least 24 hours before obtaining the procedure), "24 hour" laws, (requiring patients to wait at least 24 hours from making their appointment before obtaining an abortion without a requisite in-person visit), or no waiting period law. The second policy measure was whether minors lived in a state with parental involvement laws, including parental notification and parental consent laws. Demographic variables included age, U.S.-born or not, education level, poverty status (according to percent of federal poverty level), relationship status, parity, and race/ethnicity. Race/ethnicity was measured by first asking "Are you Spanish, Hispanic, or Latina?' and then asking respondents to choose one or more races they consider themselves to be. Responses were coded into the following categories: black, white, Asian or Pacific Islander, Hispanic, or Other. "Other" includes respondents who chose American Indian, Other, or marked more than one race. We coded respondents who identified as Spanish, Hispanic, or Latina as Hispanic regardless of race. Situational variables included the number of disruptive life events the abortion patient experienced over the last year, pregnancy gestational length ( $\leq 12$ weeks, $13-15$ weeks, and $\geq 16$ weeks) and how they paid for the abortion. We also categorized patients by region (Northeast, Midwest, South, and West), whether they lived in an MSA, and whether they crossed state lines to obtain an abortion.

We tabulated the percent distributions of patient characteristics overall and by category of distance traveled using Chi-square statistics to assess significant differences. We modeled all variables using ordered logistic regression model, a regression technique that assumes that the proportional relationship between each pair of outcome groups is the same. In other words, the relationship between those traveling the least distance compared with all higher categories of distance is the same as relationship between the next lowest category and all higher categories. Margins were calculated to obtain predicted probabilities of each category of distance traveled for the selected characteristics while holding all covariates at their means.

We also report travel distance by reasons patients chose the facility where they obtained their abortion. In response to the question "Which, if any, of the below influenced your decision to come to THIS particular facility?," patients could choose as many of the 11 closed-ended responses and "Some other reason" (which included a write-in text box) as applied to them. We present the nine most commonly reported reasons; all other reasons were reported by $\leq 1 \%$ of respondents each. We compared the average distance traveled and distance to the nearest provider among those who chose each reason to the distances of those who did not choose that reason using t-tests. We conducted all analyses in Stata version 14.1 (StataCorp, College Station, TX).

\section{Results}

Abortion patients traveled a mean of 34 miles one-way to the facility where they obtained their abortions, with a median of 16 miles (Table 1). Two-thirds $(65 \%)$ of abortion patients traveled less than 25 miles, $17 \%$ traveled $25-49$ miles, $10 \%$ traveled 50-100 miles, and 8\% traveled more than 100 miles. The mean distance to the nearest provider was 22 miles, with a median of 9 miles. Nearly half of all abortion patients obtained an abortion at their nearest provider (47\%), and 6\% traveled $\geq 50$ miles farther than their nearest provider.

Demographic characteristics of U.S. abortion patients in 2014 have been published elsewhere, ${ }^{20,22}$ but we describe several variables not previously reported; for example, $89 \%$ of abortion patients resided in an MSA (Table 2). Among abortion patients aged 17 and younger, 55\% lived in state requiring parental involvement to obtain an abortion. Nearly a quarter $(24 \%)$ of abortion patients lived in a state with a two-visit waiting period law.

Table 1. Weighted Mean, Median, and Percent Distribution of 2014 U.S. Abortion Patients by Miles

Traveled to Abortion Facility, Lived from Nearest Abortion Facility, and Traveled Beyond Nearest Facility (Unweighted $N=7,688$; Weighted $N=889,142$ Nonhospital Abortions)

\begin{tabular}{|c|c|c|c|c|c|c|c|c|}
\hline & Mean & \multicolumn{2}{|r|}{$95 \% C I$} & \multicolumn{2}{|c|}{ Median } & \multicolumn{3}{|c|}{$95 \% C I$} \\
\hline Miles traveled to abortion facility & 33.5 & \multicolumn{2}{|r|}{$28.2-38.7$} & \multicolumn{2}{|c|}{15.7} & \multicolumn{3}{|c|}{$13.6-17.8$} \\
\hline Miles to nearest abortion facility & 22.0 & \multicolumn{2}{|r|}{$17.1-26.9$} & \multicolumn{2}{|c|}{9.3} & \multicolumn{3}{|c|}{$7.7-11.0$} \\
\hline \multirow[t]{4}{*}{ Miles traveled beyond nearest abortion facility } & 12.2 & & $10.5-13.9$ & \multicolumn{2}{|c|}{1.8} & \multicolumn{2}{|c|}{$0.0-3.6$} & \\
\hline & \multicolumn{8}{|c|}{ Miles } \\
\hline & \multicolumn{2}{|l|}{$<25$} & \multicolumn{2}{|l|}{$25-49$} & \multicolumn{2}{|l|}{$50-100$} & \multicolumn{2}{|l|}{$>100$} \\
\hline & Weighted $\mathrm{n}$ & $\%$ & Weighted $\mathrm{n}$ & $\%$ & Weighted $\mathrm{n}$ & $\%$ & Weighted $\mathrm{n}$ & $\%$ \\
\hline Miles traveled to abortion facility & 579,365 & 65.2 & 154,622 & 17.4 & 87,483 & 9.8 & 67,744 & 7.6 \\
\hline Miles lived from nearest abortion facility & 690,152 & 77.6 & 101,629 & 11.4 & 63,485 & 7.1 & 33,876 & 3.8 \\
\hline Miles traveled beyond nearest abortion facility & 782,267 & 88.0 & 50,770 & 5.7 & 32,987 & 3.7 & 23,118 & 2.6 \\
\hline Miles traveled beyond nearest abortion facility & \multicolumn{2}{|c|}{ Weighted $\mathrm{n}$} & $\%$ & & & & & \\
\hline Traveled to nearest & \multicolumn{2}{|c|}{421,453} & 47.4 & & & & & \\
\hline Within 15 & \multicolumn{2}{|c|}{296,262} & 33.3 & & & & & \\
\hline 15-49 beyond & \multirow{2}{*}{\multicolumn{2}{|c|}{$\begin{array}{r}115,322 \\
56,105\end{array}$}} & 13.0 & & & & & \\
\hline$\geq 50$ beyond & & & 6.3 & & & & & \\
\hline
\end{tabular}

CI, confidence interval. 
Table 2. Percent Distributions of 2014 U.S. Abortion Patients by Selected Characteristics and Miles Traveled to Abortion Facility (Unweighted $N=7,688$; Weighted $N=889,142$ Nonhospital Abortions)

\begin{tabular}{|c|c|c|c|c|c|c|c|}
\hline Characteristic & Weighted $n$ & $\%$ & $<25$ & $25-49$ & $50-100$ & $>100$ & $\mathrm{p}$-Value \\
\hline All & & & 65.2 & 17.4 & 9.8 & 7.6 & \\
\hline Waiting period law & & & & & & & 0.00 \\
\hline Two visit requirement & 210,904 & 23.7 & 59.9 & 17.4 & 12.9 & 9.9 & \\
\hline Waiting period requirement & 189,832 & 21.4 & 52.8 & 19.5 & 13.9 & 13.8 & \\
\hline No waiting period law & 488,495 & 54.9 & 72.2 & 16.6 & 6.9 & 4.2 & \\
\hline Parental notification and consent & & & & & & & \\
\hline Limited to $<18^{\mathrm{a}}$ & & & & & & & 0.02 \\
\hline Yes & 17,607 & 54.9 & 60.6 & 19.7 & 9.0 & 10.7 & \\
\hline No & 14,464 & 45.1 & 79.7 & 10.1 & 8.0 & 2.2 & \\
\hline Age & & & & & & & 0.43 \\
\hline$<18$ & 32,071 & 3.6 & 69.2 & 15.4 & 8.5 & 6.9 & \\
\hline $18-19$ & 74,795 & 8.4 & 66.1 & 15.9 & 9.9 & 8.2 & \\
\hline $20-24$ & 300,352 & 33.8 & 63.8 & 16.9 & 10.9 & 8.4 & \\
\hline $25-29$ & 236,512 & 26.6 & 65.5 & 18.3 & 9.4 & 6.8 & \\
\hline $30-34$ & 139,151 & 15.7 & 66.0 & 17.7 & 8.7 & 7.6 & \\
\hline $35-39$ & 80,396 & 9.0 & 63.8 & 18.9 & 9.4 & 7.9 & \\
\hline $40+$ & 25,883 & 2.9 & 69.9 & 15.1 & 10.6 & 4.4 & \\
\hline Race/ethnicity & & & & & & & 0.00 \\
\hline Non-Hispanic White & 346,232 & 38.9 & 55.1 & 21.8 & 13.0 & 10.1 & \\
\hline Non-Hispanic Black & 247,537 & 27.8 & 72.7 & 12.9 & 8.9 & 5.5 & \\
\hline Hispanic & 216,951 & 24.4 & 72.9 & 15.5 & 6.9 & 4.6 & \\
\hline Non-Hispanic Asian or Pacific Islander & 48,583 & 5.5 & 70.6 & 16.7 & 6.4 & 6.4 & \\
\hline Non-Hispanic Other & 29,813 & 3.4 & 53.6 & 18.4 & 7.6 & 20.3 & \\
\hline Born in the United States & & & & & & & 0.00 \\
\hline Yes & 748,924 & 84.2 & 63.5 & 17.8 & 10.6 & 8.2 & \\
\hline No & 140,218 & 15.8 & 74.1 & 15.3 & 5.9 & 4.7 & \\
\hline Highest level of education & & & & & & & 0.00 \\
\hline Less than high school & 109,631 & 12.3 & 72.2 & 13.3 & 9.4 & 5.1 & \\
\hline High school graduate & 259,985 & 29.2 & 65.9 & 16.4 & 10.0 & 7.8 & \\
\hline Some college & 351,211 & 39.5 & 62.4 & 19.0 & 10.4 & 8.3 & \\
\hline College graduate & 168,315 & 18.9 & 65.2 & 18.4 & 8.7 & 7.7 & \\
\hline Poverty status & & & & & & & 0.07 \\
\hline$<100 \%$ & 439,770 & 49.5 & 66.7 & 16.0 & 10.1 & 7.2 & \\
\hline $100 \%-199 \%$ & 227,709 & 25.6 & 63.8 & 17.9 & 10.0 & 8.4 & \\
\hline $200+\%$ & 221,663 & 24.9 & 63.6 & 19.6 & 9.2 & 7.6 & \\
\hline Relationship status & & & & & & & 0.03 \\
\hline Married & 123,591 & 13.9 & 62.5 & 19.8 & 9.9 & 7.9 & \\
\hline Cohabitating & 278,124 & 31.3 & 65.5 & 18.2 & 8.9 & 7.4 & \\
\hline Never married & 409,806 & 46.1 & 66.6 & 16.1 & 9.9 & 7.4 & \\
\hline Previously married & 77,640 & 8.7 & 60.6 & 17.6 & 12.6 & 9.2 & \\
\hline Number previous births & & & & & & & 0.57 \\
\hline 0 & 361,614 & 40.7 & 66.0 & 16.9 & 9.4 & 7.7 & \\
\hline $1-2$ & 400,825 & 45.1 & 63.8 & 18.0 & 10.5 & 7.7 & \\
\hline 3 or more & 126,703 & 14.3 & 66.9 & 17.0 & 8.9 & 7.3 & \\
\hline Gestation (weeks from LMP) & & & & & & & 0.00 \\
\hline$\leq 12$ weeks & 799,872 & 90.0 & 65.9 & 17.4 & 9.5 & 7.1 & \\
\hline $13-15$ weeks & 52,753 & 5.9 & 61.5 & 16.9 & 11.0 & 10.6 & \\
\hline $16+$ weeks & 36,544 & 4.1 & 53.4 & 17.1 & 15.7 & 13.8 & \\
\hline Crossed state line for abortion & & & & & & & 0.00 \\
\hline Yes & 56,487 & 6.4 & 26.8 & 15.6 & 21.4 & 36.2 & \\
\hline No & 832,681 & 93.7 & 67.8 & 17.5 & 9.1 & 5.7 & \\
\hline Resides in MSA & & & & & & & 0.00 \\
\hline Yes & 791,959 & 89.1 & 71.4 & 17.1 & 7.4 & 4.1 & \\
\hline No & 97,183 & 10.9 & 14.7 & 19.7 & 29.6 & 36.0 & \\
\hline Region of residence & & & & & & & 0.00 \\
\hline Northeast & 207,081 & 23.3 & 77.8 & 14.5 & 5.8 & 1.9 & \\
\hline Midwest & 122,257 & 13.8 & 50.2 & 22.4 & 13.0 & 14.4 & \\
\hline South & 309,688 & 34.8 & 59.3 & 19.0 & 12.7 & 9.0 & \\
\hline West & 250,027 & 28.1 & 69.3 & 15.4 & 8.0 & 7.3 & \\
\hline
\end{tabular}


TABle 2. (CONTINUED)

\begin{tabular}{|c|c|c|c|c|c|c|c|}
\hline Characteristic & Weighted $n$ & $\%$ & $<25$ & $25-49$ & $50-100$ & $>100$ & $\mathrm{p}$-Value \\
\hline Number disruptive life events & & & & & & & 0.42 \\
\hline 0 & 386,599 & 43.5 & 65.1 & 17.6 & 9.7 & 7.5 & \\
\hline 1 & 292,617 & 32.9 & 66.4 & 17.2 & 9.2 & 7.3 & \\
\hline 2 or more & 209,926 & 23.6 & 63.4 & 17.3 & 11.0 & 8.3 & \\
\hline Abortion payment method & & & & & & & 0.00 \\
\hline Out of pocket/self & 414,696 & 46.6 & 59.8 & 18.4 & 11.8 & 10.1 & \\
\hline Financial assistance & 121,990 & 13.7 & 59.4 & 19.4 & 11.2 & 10.0 & \\
\hline Private insurance & 125,814 & 14.2 & 70.2 & 18.4 & 7.7 & 3.7 & \\
\hline Medicaid & 210,460 & 23.7 & 74.6 & 14.2 & 6.8 & 4.5 & \\
\hline Other & 16,191 & 1.8 & 72.9 & 16.5 & 7.1 & 3.5 & \\
\hline
\end{tabular}

${ }^{a}$ Not all variables in distance sample contain the full 7688 cases as a small number of cases may be missing.

LMP, last menstrual period; MSA, metropolitan statistical area.

Several characteristics were associated with travel distance in unadjusted analyses. The proportion of patients living in a state with a two-visit waiting period law were twice as likely as those who lived in a state with no waiting period to have traveled more than 100 miles one-way (10\% vs. $4 \%$ ); those in states with waiting period laws not requiring two visits were three times as likely (14\% vs. $4 \%)$. Among abortion patients aged 17 and younger, $11 \%$ of those in a parental involvement state traveled more than 100 miles compared with $2 \%$ in states with no such law. White patients and "other" race/ethnicity-identified patients were most likely to travel more than 100 miles $(10 \%$ and $20 \%$, respectively); only between $5 \%$ and $6 \%$ of black, Latina/o, and Asian patients traveled more than 100 miles. There were no differences in travel distance by age, number of previous births, number of disruptive life events, or poverty level.

The proportion of abortion patients at $\geq 16$ weeks of gestation who traveled more than 100 miles was twice that of those at $\leq 12$ weeks $(14 \%$ vs. $7 \%)$. Patients who crossed state lines for their abortion were eight times more likely to travel more than 100 miles than those who did not (36\% vs. 4\%) Abortion patients living outside an MSA were eight times more likely to travel more than 100 miles than MSA-resident abortion patients ( $36 \%$ vs. $4 \%$ ).

Abortion patients from the Midwest had the smallest proportion of patients traveling less than 25 miles (50\%) for an abortion and the greatest proportion traveling more than 100 miles (14\%). In contrast, more than three quarters of Northeast-resident abortion patients traveled less than 25 miles, and just $2 \%$ traveled more than 100 miles.

Most associations in the bivariate analysis were maintained after controlling for other variables with the exception of region of residence and marital status ${ }^{\dagger}$ (Table 3). Patients who lived in a state with a required waiting period (but without a two-visit requirement) had more than 1.5 times the odds of traveling each category of distance farther compared to those who lived in states with no waiting period. Black patients were half as likely to travel each category of distance farther compared with white patients, and non-MSA residents had 12 times greater odds of traveling compared to MSA residents. Compared to patients with some college education,

\footnotetext{
$\dagger$ Living in a parental involvement state was not in the adjusted model because such policies only affect minors and the model was not restricted to minors.
}

those with less than a high school education had 30\% lower odds of traveling each category of distance farther. Compared to those obtaining abortions at $\leq 12$ weeks of pregnancy, patients obtaining abortions at 13-15 weeks had 1.5 times greater odds of traveling each category of distance farther, and those at $\geq 16$ weeks had 2.8 times the odds of traveling farther. Patients using private insurance to cover their abortion had $20 \%$ lower odds of traveling each category further compared to those paying out-of-pocket. Patients who crossed state lines for abortion services had five times greater odds of traveling each category of distance farther compared to those obtaining an abortion in their state of residence.

When asked why they obtained an abortion at the particular facility they did, $66 \%$ of respondents chose one reason; $30 \%$ gave more than one reason, and 5\% gave no reason (not shown). Among abortion patients who provided a reason, nearly one-third $(32 \%)$ said they chose their particular facility because it was the closest (Table 4). There was no difference in average miles traveled between those who went to their facility because it was closest and those who did not choose this reason; however, those who chose their facility because it was closest lived farther from their nearest provider compared with those who did not choose that reason (27 vs. 20 miles, $p<0.01$ ).

Abortion patients reported several aspects of clinical services that influenced their decision of facility. The $13 \%$ of abortion patients who chose their facility because it could schedule them the soonest traveled an average of 41 miles whereas those who did not choose this reason traveled an average of 32 miles $(p<0.01)$, although there was no difference in distance to the nearest abortion facility between these groups.

Similarly, the $2 \%$ of abortion patients who were too far along in pregnancy to go to other providers traveled an average of 72 miles compared to an average of 33 miles traveled by those who did not choose this reason $(p<0.01)$. Notably, when restricting the comparison to only those patients who obtained abortions at $<16$ weeks, those who were too far along still traveled farther on average-68 miles compared with 33 among those who did not choose this reason $(p<0.01)$ (not shown).

The $15 \%$ of patients who chose their clinic because it offered medication abortion lived on average closer to their nearest clinic ( 20 vs. 23 miles, $p<0.001$ ) and traveled a shorter average distance ( 28 vs. 35 miles, $p<0.01$ ) than those who did not. Similarly, those who chose their clinic because it 
Table 3. Proportional Odds Ratios and 95\% Confidence Intervals for Selected 2014 U.S. Abortion Patient Characteristics and Category of Miles Traveled to Abortion Facility and Their Predicted Probabilities, Holding All Other Variables at Their Means $(N=7,406)$

\begin{tabular}{|c|c|c|c|c|c|c|c|}
\hline Characteristic & $O R$ & $\mathrm{p}$-Value & $C I$ & $<25$ & $25-49$ & $50-100$ & $>100$ \\
\hline \multicolumn{8}{|l|}{ Waiting period law } \\
\hline Two visit requirement & 1.4 & 0.099 & $0.9-2.0$ & 62.9 & 22.4 & 10.0 & 4.7 \\
\hline Waiting period requirement & 1.7 & 0.043 & $1.0-2.8$ & 57.8 & 24.6 & 11.9 & 5.7 \\
\hline No waiting period law & ref & - & - & 69.8 & 19.0 & 7.8 & 3.5 \\
\hline \multicolumn{8}{|l|}{ Age } \\
\hline$<18$ & 1.3 & 0.174 & $0.9-1.8$ & 58.7 & 24.2 & 11.5 & 5.5 \\
\hline $18-19$ & 0.9 & 0.321 & $0.7-1.1$ & 66.8 & 20.5 & 8.7 & 4.0 \\
\hline $20-24$ & ref & - & - & 64.2 & 21.8 & 9.6 & 4.4 \\
\hline $25-29$ & 0.9 & 0.254 & $0.8-1.1$ & 66.0 & 20.9 & 9.0 & 4.1 \\
\hline $30-34$ & 0.9 & 0.133 & $0.7-1.0$ & 67.6 & 20.1 & 8.5 & 3.8 \\
\hline $35-39$ & 0.9 & 0.398 & $0.7-1.1$ & 66.2 & 20.8 & 8.9 & 4.1 \\
\hline $40+$ & 0.7 & 0.027 & $0.5-1.0$ & 72.8 & 17.3 & 6.8 & 3.0 \\
\hline \multicolumn{8}{|l|}{ Race/ethnicity } \\
\hline Non-Hispanic White & ref & - & - & 60.2 & 23.6 & 11.0 & 5.2 \\
\hline Non-Hispanic Black & 0.5 & 0.000 & $0.4-0.6$ & 74.9 & 16.1 & 6.2 & 2.7 \\
\hline Hispanic & 0.8 & 0.104 & $0.6-1.0$ & 65.1 & 21.3 & 9.3 & 4.3 \\
\hline Non-Hispanic Asian or Pacific Islander & 0.9 & 0.547 & $0.6-1.3$ & 62.7 & 22.5 & 10.1 & 4.7 \\
\hline Non-Hispanic Other & 1.3 & 0.081 & $1.0-1.9$ & 52.9 & 26.4 & 13.7 & 6.9 \\
\hline \multicolumn{8}{|l|}{ Born in the United States } \\
\hline Yes & 1.3 & 0.009 & $1.1-1.6$ & 64.8 & 21.5 & 9.4 & 4.3 \\
\hline No & ref & - & - & 70.6 & 18.5 & 7.5 & 3.4 \\
\hline \multicolumn{8}{|l|}{ Highest level of education } \\
\hline Less than high school & 0.7 & 0.004 & $0.6-0.9$ & 70.6 & 18.5 & 7.5 & 3.4 \\
\hline High school graduate & 0.9 & 0.054 & $0.7-1.0$ & 66.5 & 20.7 & 8.8 & 4.0 \\
\hline Some college & ref & - & - & 63.1 & 22.3 & 10.0 & 4.7 \\
\hline College graduate & 0.9 & 0.092 & $0.7-1.0$ & 66.7 & 20.5 & 8.7 & 4.0 \\
\hline \multicolumn{8}{|l|}{ Poverty status } \\
\hline$<100 \%$ & ref & - & - & 65.0 & 21.4 & 9.3 & 4.3 \\
\hline $100-199 \%$ & 1.0 & 0.574 & $0.8-1.1$ & 66.0 & 20.9 & 9.0 & 4.1 \\
\hline $200+\%$ & 0.9 & 0.403 & $0.8-1.1$ & 66.7 & 20.6 & 8.8 & 4.0 \\
\hline \multicolumn{8}{|l|}{ Relationship status } \\
\hline Married & 1.1 & 0.169 & $1.0-1.3$ & 63.0 & 22.3 & 10.0 & 4.7 \\
\hline Cohabitating & 0.9 & 0.166 & $0.8-1.0$ & 67.7 & 20.0 & 8.4 & 3.8 \\
\hline Never married & ref & - & - & 65.7 & 21.0 & 9.1 & 4.2 \\
\hline Previously married & 1.2 & 0.114 & $1.0-1.4$ & 62.3 & 22.6 & 10.2 & 4.8 \\
\hline \multicolumn{8}{|l|}{ Number previous births } \\
\hline 0 & 0.9 & 0.082 & $0.8-1.0$ & 67.3 & 20.2 & 8.5 & 3.9 \\
\hline $1-2$ & ref & - & - & 64.4 & 21.7 & 9.5 & 4.4 \\
\hline 3 or more & 1.0 & 0.807 & $0.8-1.2$ & 64.9 & 21.4 & 9.3 & 4.3 \\
\hline \multicolumn{8}{|l|}{ Number disruptive life events } \\
\hline 0 & ref & - & - & 65.5 & 21.1 & 9.2 & 4.2 \\
\hline 1 & 1.0 & 0.661 & $0.8-1.1$ & 66.2 & 20.8 & 8.9 & 4.1 \\
\hline 2 or more & 1.0 & 0.926 & $0.9-1.2$ & 65.3 & 21.2 & 9.2 & 4.2 \\
\hline \multicolumn{8}{|l|}{ Gestation (weeks LMP) } \\
\hline$\leq 12$ weeks & ref & - & - & 67.2 & 20.3 & 8.6 & 3.9 \\
\hline 13-15 weeks & 1.5 & 0.008 & $1.1-2.0$ & 57.9 & 24.5 & 11.8 & 5.7 \\
\hline $16+$ weeks & 2.8 & 0.000 & $1.7-4.8$ & 42.0 & 29.2 & 18.5 & 10.3 \\
\hline \multicolumn{8}{|l|}{ Abortion payment method } \\
\hline Out of pocket/self & ref & - & - & 63.5 & 22.1 & 9.8 & 4.6 \\
\hline Financial assistance & 0.9 & 0.284 & $0.7-1.1$ & 65.9 & 21.0 & 9.0 & 4.1 \\
\hline Private insurance & 0.8 & 0.018 & $0.7-1.0$ & 68.1 & 19.9 & 8.3 & 3.8 \\
\hline Medicaid & 0.8 & 0.184 & $0.6-1.1$ & 68.1 & 19.8 & 8.3 & 3.8 \\
\hline Other & 0.8 & 0.232 & $0.5-1.2$ & 69.2 & 19.3 & 7.9 & 3.6 \\
\hline \multicolumn{8}{|l|}{ Region of residence } \\
\hline Northeast & 0.6 & 0.063 & $0.4-1.0$ & 74.1 & 16.6 & 6.4 & 2.8 \\
\hline Midwest & 1.1 & 0.563 & $0.7-1.7$ & 60.3 & 23.6 & 11.0 & 5.2 \\
\hline South & ref & - & - & 63.2 & 22.2 & 9.9 & 4.6 \\
\hline West & 1.0 & 0.922 & $0.6-1.5$ & 63.7 & 22.0 & 9.7 & 4.5 \\
\hline \multicolumn{8}{|l|}{ Resides in MSA } \\
\hline Yes & ref & - & - & 71.5 & 18.0 & 7.2 & 3.2 \\
\hline No & 11.6 & 0.000 & $6.7-20.1$ & 17.8 & 24.7 & 29.7 & 27.8 \\
\hline Crossed state line for abortion & & & & & & & \\
\hline Yes & 5.2 & 0.000 & $3.1-8.7$ & 29.2 & 29.3 & 24.7 & 16.8 \\
\hline No & ref & - & - & 68.0 & 19.9 & 8.3 & 3.8 \\
\hline
\end{tabular}

OR, odds ratio. 
Table 4. Percent Distribution of 2014 U.S. Abortion Patients' Reasons for Choosing Abortion Facility (Among Those Who Provided $\geq 1$ Reason)

\begin{tabular}{|c|c|c|c|c|c|c|c|}
\hline & \multirow[b]{2}{*}{$\%$ Yes } & \multicolumn{2}{|c|}{$\begin{array}{l}\text { Average Miles to Nearest } \\
\text { Provider By Reason }\end{array}$} & \multirow[b]{2}{*}{$\mathrm{p}$-Value } & \multicolumn{2}{|c|}{$\begin{array}{c}\text { Average Miles } \\
\text { Traveled By Reason }\end{array}$} & \multirow[b]{2}{*}{$\mathrm{p}$-Value } \\
\hline & & Yes & No & & Yes & No & \\
\hline It was the closest & 31.9 & 27.4 & 19.7 & 0.01 & 35.0 & 32.9 & 0.49 \\
\hline I have been here before & 20.2 & 16.6 & 23.6 & 0.001 & 23.3 & 36.1 & 0.001 \\
\hline $\begin{array}{l}\text { It was recommended to me by a friend, } \\
\text { family member or someone I trust }\end{array}$ & 17.5 & 20.1 & 22.6 & 0.03 & 29.5 & 34.4 & 0.001 \\
\hline It offers medication abortion & 15.2 & 19.6 & 22.7 & 0.03 & 28.4 & 34.5 & 0.001 \\
\hline It was the most affordable & 14.6 & 21.6 & 22.3 & 0.71 & 34.4 & 33.4 & 0.68 \\
\hline It could see me the soonest & 13.1 & 23.6 & 22.0 & 0.42 & 41.1 & 32.4 & 0.001 \\
\hline $\begin{array}{l}\text { It was recommended to me by another } \\
\text { health care provider }\end{array}$ & 11.3 & 24.1 & 21.9 & 0.50 & 38.4 & 32.9 & 0.10 \\
\hline It takes my insurance & 10.4 & 16.5 & 22.8 & 0.01 & 27.2 & 34.3 & 0.01 \\
\hline $\begin{array}{l}\text { I am too far along in my pregnancy } \\
\text { to go to other providers }\end{array}$ & 2.1 & 21.3 & 22.2 & 0.82 & 72.0 & 32.7 & 0.001 \\
\hline
\end{tabular}

Respondents indicated as many answers as applied to them; \%s will not sum to 100.

took their insurance lived closer to their nearest clinic (17 vs. 23 miles, $p<0.01)$ and traveled a shorter average distance (27 vs. 34 miles, $p<0.01$ ) compared to those who did not report this reason.

\section{Discussion and Conclusions}

This study provides the first update of the distance U.S. abortion patients actually traveled one-way to the facility where they obtained care since the baseline was established in 2008. Nearly two-thirds of abortion patients $(65 \%)$ traveled less than 25 miles for services in 2014, a proportion similar to the 2008 estimate of $67 \%,{ }^{5}$ despite some changes in the abortion service landscape and the national abortion patient profile since that time. Still, more than $17 \%$ of those obtaining an abortion in 2014-some 155,000 peopletraveled 50 miles or more for abortion care. We also show that the provider being the closest was a main reason abortion patients chose their facility and that nearly half of all abortion patients traveled to their nearest provider, indicating that distance is an important determinant of abortion access.

Some groups of abortion patients were more likely to travel farther in 2014, in particular, more than 100 miles, compared to their counterparts. White patients, collegeeducated, and U.S.-born patients were more likely to travel farther for an abortion, which may reflect that these groups have more material, informational, and social resources to be able to travel, while those without the resources to travel the same distances are not represented in this sample if they were unable to overcome those obstacles. Farther travel among patients at higher gestational lengths likely reflects that abortion services at the second trimester are less commonly available and those patients therefore must travel beyond their nearest provider to obtain care. Notably, $36 \%$ of patients residing in non-MSA regions traveled more than 100 miles for abortion services, the largest proportion of any group, reflecting a considerable travel burden where services are not geographically accessible. ${ }^{21}$

We also found that abortion patients who lived in states with two-visit requirements and adolescents who lived in parental notification states traveled farther. While these policies in and of themselves do not affect distance to a clinic, states with these restrictions may also be more likely to enforce restrictions that lead to clinic closures or prevent providers from offering abortion care. For example, in 2010 every state with a two-visit law also enforced at least two other major abortion restrictions. ${ }^{23}$ If so, this finding is concerning given that emerging research has shown that multiple restrictions compound the burden of obtaining abortion care, particularly for those who already have limited resources to overcome them. ${ }^{7,9}$

This is the first U.S. study to assess the proportion of abortion patients who traveled beyond their nearest provider, how much farther they traveled, and the reasons they chose the clinic they did. Most abortion patients (81\%) went to their nearest provider or within 15 miles of their nearest provider, and nearly one-third said they chose their clinic because it was the closest. While distance was the most common reason abortion patients chose their facility, this was just one factor they weighed. There was no one majority reason for abortion patients' choice of facility and more than a third of respondents reported two or more reasons. Our results suggest that some individuals travel farther to get the care that is best for them. Both abortion patients who reported they chose their facility because it provided the soonest appointment and those who reported they were too far along in pregnancy for other providers traveled substantially farther for care compared to those who did not give these reasons, despite no difference in distance to the nearest provider between the groups.

It is important to note that we describe crude associations between distance and reasons for clinic choice, and some associations likely are not due to distance, per se. For example, it is possible that patients who lived in urban areas, and therefore closer to providers, were able to prioritize reasons for clinic choice that did not relate to distance.

A limitation of this study is that data came from individuals who obtained abortions; therefore, those who were unable to present at an abortion facility-because of distance or other barriers, such as gestational limits-are not included. The Turnaway Study, which documented the experiences of people unable to obtain an abortion because of clinic gestational 
limits, found that a primary reason for delays is time spent gathering funds for procedure and travel costs, and that some 4,000 such people per year may be denied wanted abortion care. ${ }^{8}$ Another limitation is that this nationally representative study cannot detect changes in distance traveled at the state or region level where clinic closures may have left some areas with fewer or no providers. For example, more than half of Texas abortion facilities closed after a restrictive abortion law, House Bill 2, was introduced in 2013 and this led to the distance to the nearest abortion facility to increase from 15 to 35 miles among 2014 Texas abortion patients. ${ }^{7}$ Finally, our survey excluded patients obtaining abortions in hospitals, where an estimated $4 \%$ of abortions were provided in $2014 .^{3}$ If hospital abortion patients traveled closer or farther than nonhospital abortion patients, our distance estimates could be biased.

Emergent models of health care delivery could reduce the travel burden among rural individuals in particular. Pharmacy provision of medication abortion could reduce travel distance for abortion patients; however, the Food and Drug Administration's Risk Evaluation and Mitigation Strategy (REMS) for one of the drugs used in early medication abortion, mifepristone, prohibits dispensing it by pharmacy prescription. Current evidence regarding the safety of mifepristone indicates that the REMS is not necessary. ${ }^{24}$ Similarly, telemedicine is used to deliver a range of reproductive health services ${ }^{25}$ and is safe and effective for the provision of medication abortion. ${ }^{26-28}$ Currently, 17 U.S. states ban telemedicine for abortion care specifically, despite evidence that it is safe, effective, and highly accepted by abortion patients. ${ }^{29}$

Distance is a relative measure of one cost of obtaining an abortion. The burden travel places upon obtaining medical care depends on an individuals' context and resources, including access to private and public transportation, childcare, and paid sick time. Most individuals seeking abortion services in the United States are low-income, ${ }^{20}$ and a nearly a third of patients said they chose their clinic because it was closest, suggesting that farther distances may be a salient barrier to timely and appropriate abortion care for many abortion patients. One study found that the national average distance traveled for medical/dental care was 10 miles, ${ }^{30}$ while in 2014, U.S. abortion patients traveled on average 34 miles-three times farther. This farther travel is an added burden that abortion patients face, as they also consider factors such as restrictive abortion laws, cost, scheduling, and service type, to obtain the care they need.

\section{Author Disclosure Statement}

No competing financial interests exist.

\section{References}

1. Arcury TA, Gesler WM, Preisser JS, Sherman J, Spencer J, Perin J. The effects of geography and spatial behavior on health care utilization among the residents of a rural region. Health Serv Res 2005;40:135-155.

2. Guagliardo MF. Spatial accessibility of primary care: Concepts, methods and challenges. Int $\mathrm{J}$ Health Geogr 2004;3:3.

3. Jones RK, Jerman J. Abortion incidence and service availability in the United States, 2014. Perspect Sex Reprod Health 2017;49:17-27.
4. Bureau UC. 2010 Office of Management and Budget (OMB) Standards. Available at: https://www.census.gov/ programs-surveys/metro-micro/about/omb-standards.html Accessed February 21, 2019.

5. Jones RK, Jerman J. How far did US women travel for abortion services in 2008? J Womens Health 2013;22:706713.

6. Roberts SC, Fuentes L, Kriz R, Williams V, Upadhyay UD. Implications for women of Louisiana's law requiring abortion providers to have hospital admitting privileges. Contraception 2015;91:368-372.

7. Gerdts C, Fuentes L, Grossman D, et al. Impact of clinic closures on women obtaining abortion services after implementation of a restrictive law in Texas. Am J Public Health 2016;106:857-864.

8. Upadhyay UD, Weitz TA, Jones RK, Barar RE, Foster DG. Denial of abortion because of provider gestational age limits in the United States. Am J Public Health 2014;104: 1687-1694.

9. Jerman J, Frohwirth L, Kavanaugh ML, Blades N. Barriers to abortion care and their consequences for patients traveling for services: Qualitative findings from two states. Perspect Sex Reprod Health 2017;49:95-102.

10. Upadhyay UD, Johns NE, Meckstroth KR, Kerns JL. Distance traveled for an abortion and source of care after abortion. Obstet Gynecol 2017;130:616.

11. White K, deMartelly V, Grossman D, Turan JM. Experiences accessing abortion care in Alabama among women traveling for services. Womens Health Issues 2016;26:298304.

12. Joyce $\mathrm{T}$, Tan R, Zhang Y. Abortion before \& after Roe. J Health Econ 2013;32:804-815.

13. Quast T, Gonzalez F, Ziemba R. Abortion facility closings and abortion rates in Texas. Inquiry 2017;54:46958017700944.

14. Shelton JD, Brann EA, Schulz KF. Abortion utilization: Does travel distance matter? Fam Plann Perspect 1976;8: 260-262.

15. Sethna C, Doull M. Spatial disparities and travel to freestanding abortion clinics in Canada. Womens Stud Int Forum 2013;38:52-62.

16. Grossman D, Baum S, Fuentes L, et al. Change in abortion services after implementation of a restrictive law in Texas. Contraception 2014;90:496-501.

17. Grossman D, White K, Hopkins K, Potter JE. Change in distance to nearest facility and abortion in Texas, 2012 to 2014. JAMA 2017;317:437-439.

18. Colman S, Joyce T. Regulating abortion: Impact on patients and providers in Texas. J Policy Anal Manage 2011;30: 775-797.

19. Henshaw SK. Factors hindering access to abortion services. Fam Plann Perspect 1995;27:54-59, 87.

20. Jerman J, Jones Rachel K, Onda T. Characteristics of US abortion patients in 2014 and changes since 2008. New York, NY: Guttmacher Institute, 2017.

21. Bearak JM, Burke KL, Jones RK. Disparities and change over time in distance women would need to travel to have an abortion in the USA: A spatial analysis. Lancet Public Health 2017;2:e493-e500.

22. Jones RK, Jerman J. Time to appointment and delays in accessing care among US abortion patients. New York, NY: The Guttmacher Institute, 2016.

23. State abortion policy landscape: From hostile to supportive. Guttmacher Institute, 2018; published online Dec 10. Available at: https://www.guttmacher.org/article/2018/12/state-abortion- 
policy-landscape-hostile-supportive Accessed February 21, 2019.

24. Raifman S, Orlando M, Rafie S, Grossman D. Medication abortion: Potential for improved patient access through pharmacies. J Am Pharm Assoc 2018;58:377-381.

25. Mann S, McKay K, Brown H. The maternal health compact. N Engl J Med 2017;376:1304-1305.

26. Grossman DA, Grindlay $\mathrm{K}$, Buchacker $\mathrm{T}$, Potter JE, Schmertmann CP. Changes in service delivery patterns after introduction of telemedicine provision of medical abortion in Iowa. Am J Public Health 2013;103:73-78.

27. Grossman D, Grindlay K, Buchacker T, Lane K, Blanchard $\mathrm{K}$. Effectiveness and acceptability of medical abortion provided through telemedicine. Obstet Gynecol 2011;118:296303.

28. Raymond EG, Chong E, Hyland P. Increasing Access to abortion with telemedicine. JAMA Intern Med 2016;176: 585 .
29. Medication Abortion. Guttmacher Institute, 2019; published online May 1. Available at: https://www.guttmacher .org/state-policy/explore/medication-abortion Accessed May 11, 2019.

30. Probst JC, Laditka SB, Wang JY, Johnson AO. Effects of residence and race on burden of travel for care: Cross sectional analysis of the 2001 US National Household Travel Survey. BMC Health Serv Res 2007;7:40.

Address correspondence to:

Liza Fuentes, DrPH, MPH

Research Division

Guttmacher Institute

125 Maiden Lane 7th Floor

New York, NY 10038

E-mail: lfuentes@guttmacher.org 